\title{
Need for Asset Management Systems to Improve Efficiency of Biomedical Engineering Department in Hospital
}

\author{
${ }^{1}$ Amrita Patel, ${ }^{2}$ Kasturi Shukla, ${ }^{3}$ Uday Uttekar, ${ }^{4}$ Mahesh Mane, ${ }^{5}$ Rekha Dubey, ${ }^{6} \mathrm{Hem}$ Chandra
}

\begin{abstract}
Introduction: With advanced medical equipments being developed everyday, hospitals have assets that need expert maintenance in order to ensure their proper functioning. This study was undertaken to understand the problems related to asset management faced by the biomedical engineering department (BMED) at a 390 bedded tertiary hospital in Pune, Maharashtra.

Materials and methods: The cross-sectional study was conducted at a 390 bedded tertiary care hospital in Pune, India during May 2013. The BMED staff was interviewed to identify the problems faced by them in the current manual system of equipment record maintenance and the need for a computerized BMED record system. Data from January to April 2013 were analyzed to measure total number of entries/month, time required/entry and related errors.
\end{abstract}

Results: An average of 16 hours per month were spent on manual data entry of equipment maintenance and errors due to manual system led to problems like inaccurate reports to calculate breakdown time of equipments.

Conclusion: Computerized system software is the need of the hour for managing biomedical equipments. This will save many man-hours and also make the system more efficient.

Keywords: Asset, Biomedical equipment, Manual errors.

How to cite this article: Patel A, Shukla K, Uttekar U, Mane M, Dubey R, Chandra H. Need for Asset Management Systems to Improve Efficiency of Biomedical Engineering Department in Hospital. Int J Res Foundation Hosp Healthc Adm 2014;2(2): 84-86.

\footnotetext{
${ }^{1}$ Student, ${ }^{2}$ Faculty, ${ }^{3}$ Manager, ${ }^{4}$ Assistant Manager

${ }^{5}$ General Manager, ${ }^{6}$ Professor and Head

1,2Department of Post Graduate Program in Healthcare Services Program, Sancheti Healthcare Academy, Pune Maharashtra, India

${ }^{3,4}$ Department of Biomedical Engineering, Aditya Birla Memorial Hospital, Pune, Maharashtra, India

${ }^{5}$ Department of Patient Services, Aditya Birla Memorial Hospital, Pune, Maharashtra, India

${ }^{6}$ Department of Hospital Administration, Sanjay Gandhi Postgraduate Institute of Medical Sciences, Lucknow, Uttar Pradesh, India
}

Corresponding Author: Kasturi Shukla, Faculty, Department of Post Graduate Program in Healthcare Services Program Sancheti Healthcare Academy, Shivaji Nagar, Pune Maharashtra, India, e-mail: k_agnihotri1@yahoo.co.in and kasturiagnihotir@rediffmail.com

\section{Source of support: Nil}

Conflict of interest: None declared

\section{INTRODUCTION}

As the healthcare industry is focusing on achieving top-line growth, it is facing major challenges in managing medical equipment, which include tracking and managing assets, complying with ever-changing regulatory standards, guarding against equipment failures, and managing clinical equipment inventory. ${ }^{1}$ With advanced medical equipments being developed everyday, hospitals have assets that need expert maintenance in order to ensure their proper functioning. As in any high-technology enterprise, asset management in a hospital or healthcare network begins with an accurate inventory of the equipment installed, together with the ability to track the service history of each item of equipment and the related costs. ${ }^{2,3}$ In accordance to the same, this study was undertaken to understand the problems related to asset management faced by the biomedical engineering department (BMED) at a 390 bedded tertiary hospital in Pune, Maharashtra.

\section{MATERIALS AND METHODS}

Study design and settings: The cross-sectional study was conducted at a 390 bedded tertiary care hospital in Pune in the state of Maharashtra, India during the month of May 2013 after receiving approval from the hospital authorities. The selected hospital has a specialized BMED to maintain the critical as well as the noncritical medical equipments in the hospital and the authorities wanted to improve the efficiency of the presently existing manual system of data keeping at the department. This study was aimed at studying the working of the BMED and suggests recommendations for improvement if any.

Subjects: The staff working in the BMED was selected for the study. This included the senior manager, manager, four biomedical engineers and the clerk of the BMED.

Instrument: Based on the observations of work process flow at the BMED for a week, important variables for the study were identified on the basis of which the data collection methods were developed. Personal interviews were 
Need for Asset Management Systems to Improve Efficiency of Biomedical Engineering Department in Hospital

Table 1: Errors due to absence of standard data entry system

\begin{tabular}{llllll}
\hline Months & Total entries & $\begin{array}{l}\text { Errors in name of } \\
\text { equipment }\end{array}$ & $\begin{array}{l}\text { Errors in entering } \\
\text { asset codes }\end{array}$ & $\begin{array}{l}\text { Errors in entering } \\
\text { name of department }\end{array}$ & $\begin{array}{l}\text { Errors in entering } \\
\text { am/pm }\end{array}$ \\
\hline Jan.13 & 377 & 11 & 2 & 9 & 2 \\
Feb.13 & 246 & 11 & 4 & 6 & 1 \\
Mar.13 & 346 & 7 & 3 & 7 & 1 \\
Apr.13 & 323 & 2 & 2 & 4 & 0 \\
\hline
\end{tabular}

Table 2: Time required for manual data entry

\begin{tabular}{lll}
\hline Months & Total entries & $\begin{array}{l}\text { Time required for manual } \\
\text { data entry hours }\end{array}$ \\
\hline Jan. 2013 & 377 & 19 \\
Feb. 2013 & 246 & 12 \\
Mar. 2013 & 346 & 17 \\
Apr. 2013 & 323 & 16 \\
\hline
\end{tabular}

conducted individually with all the staff members of the BMED to identify the problems faced because of the current system of maintaining the records of the equipments which was a manual system. Interviews were conducted in an unstructured manner so that responses were not restricted due to structured questions. These were useful to obtain the most relevant information. It was also useful in knowing the perception of the respondents. Registers maintained at the BMED were used to gather data for the study. The sources of data were the service reports registers, annual maintenance contract and comprehensive maintenance contract registers (AMC/CMCR), Excel spread sheets maintained by the BMED staff, calibration register, scrap material register. These registers were manually maintained and updated regularly by the staff.

Study procedure: In the initial first week, an observational pilot study and personal interviews were conducted to identify the crucial variables in the records. According to the observations, the data from the registers maintained in the department were studied and analyzed to gather data on the two crucial variables, i.e. time required for manual data entry and the errors occurring during the monthly data entries.

The service reports for the equipments in the hospital were manually filled in by the biomedical engineers. At the end of the day, these reports were supposed to be refilled into the Microsoft excel sheets being maintained by the department. This computerized data were then used to generate performance reports for the equipments and to measure the down time of the critical equipments. As there was a double entry system, i.e. manual and then again into the system there was considerable time being spent on the same process. The biomedical engineers sometimes did not get time for making the computer entries and this leads to pilling up of work. Data from the months of January to April 2013 were analyzed and the following variables were measured:

- Total number of entries in each month.
- Time required for making the entries. (Average time taken by each biomedical engineer to make one entry was calculated by observing them while making the entries and noting down the time taken. This average time was then multiplied to the total number of entries).

- Errors due to absence of a standard entry system.

\section{RESULTS}

The BMED engineers work with a team of technicians and are mainly responsible for the repairs of the medical equipment in the hospital. In addition to this they are also responsible for the annual maintenance, calibration of the medical equipments and take regular rounds to check working of all the equipments. BMED engineers do the data entry of all the service reports, however due to time constraints they are sometimes unable to enter all data on the same day.

It was observed that all the data entry related to the maintenance of the equipments of the hospital was being done manually. There was no specialized software which could be used for all the data maintenance work. Maintaining separate registers for each of the details lead to segregation of data and hence it was difficult to club all the details of particular equipment at one place during decision making. Paper based registers were difficult to maintain as they had to be stored properly to prevent damage. Problems were faced when equipment was transferred from one department to other as there was no record of such transfers. There was no provision for reminders for due dates for calibration of equipment. The manager had to spend time to prepare the monthly reports to be sent to the top management as there was no provision to generate these reports automatically. As there was no customized software for data entries following problems, such as manual errors, no discipline among employees, real time updating not possible, data entry work getting piled up and then done hastily at the end of the month were faced. There was no provision for automatic generation of reports of the assets.

On an average 16 hours per month were being spent due to repetitive data entry. Manual errors were occurring as there was no standard system for entries of data (Table 1). These errors resulting in inaccurate reports while calculating the breakdown time of the equipments. There was redundancy in data entry done by the junior manager as well as the 
engineers. This led to wastage of manpower hours (Table 2). There was no provision by which the data of the assets could be linked to the hospital management system. This had a negative impact on management decision making in terms of time as they had no direct access to the data and had to ask the department for the information before taking any decision.

This table depicts the errors occurring due to the manual entry of the data. Most important are the errors occurring in the am/pm entry for the time of call received to the time the call is completed. This error causes the downtime of the equipment to be calculated in inaccurately. This incorrect calculation affects the further reports which are submitted to the top management of the hospitals.

Table 2 depicts the time required for the manual entry of the data of the equipment breakdowns. This time required doubles up when there is repetitive data entry by different employees. Thus, on an average 16 extra hours/month could be save if the system was computerized with an advantage of reduced errors.

\section{DISCUSSION}

The present study aimed at finding the problems faced by the BMED due to the current system of data entry which was manual. Analysis of the data pointed out to the flaws of using a paper based system in order to maintain the assets of the hospital. Manual errors occurring and the redundancy in the data entry led to decrease in the efficiency of the functioning of the department. The efficiency can be improved and accurate management decisions can be made by understanding the importance of using an asset management system in the hospital.

Asset management systems can help hospitals and healthcare organizations increase equipment availability, reduce operating and maintenance costs and maintain higher quality requirements. This optimized performance includes the ability to manage the complete life cycle of all critical assets - beginning with planning and procurement and extending through deployment, tracking, maintenance and disposal. ${ }^{4}$ Hospitals abroad that have embraced asset management systems developed by companies, such as Intel, Philips, IBM and Infor have realized many immediate and long-term advantages including direct, indirect and opportunity cost savings. ${ }^{4,5}$

The advantages of outsourced $v s$ hospital owned BMED can also be compared. On one hand, outsourcing provides specialized services at a fixed cost but suffers from disadvantages like difficulty in choosing the best provider, poor quality control, decreased company loyalty and a long bid process. ${ }^{6}$ On the other hand, hospital owned BMED ensures better quality control, enhanced accountability with better hospital understanding due to internal staff. In addition to electronic asset management software, the option of outsourcing vs own BMED may be considered by hospital administration for future management.

\section{CONCLUSION}

Implementation of asset management systems has helped in eliminating time-consuming manual audits. It has also improved asset reconciliation and gained the accurate data needed to more strategically plan for future data needs. In order to improve the efficiency of the department, the management should implement asset management system which will help reduce the time required for the data entry and will also reduce the number of errors occurring.

\section{REFERENCES}

1. Intermezzo 2. Asset management. Medicamundi 48/3 2004/11. Available at: http://www.healthcare.philips.com/pwc_hc/main/ about/assets/docs/medicamundi/mm vol48 no3/13 Intermezzo_2.pdf. Accessed on 18th November 2013.

2. Infor EAM Healthcare Edition (2012). Available at: www.infor. $\mathrm{com} /$ content/brochures/eam-healthcare.pdf. Accessed on: 10th December 2013.

3. Enhancing access to healthcare through innovation-Medical technology in India. PwC (2011) https://www.pwc.in/assets/ pdfs/pharma/PwC-FICCI-Medical_Technology_in_India.pdf. Accessed on: 14th January 2014.

4. Need for asset management in corporate hospitals and trust hospitals. White paper. Available at: http://www.levantare.co.in/. Accessed on 14th November 2013.

5. IBM asset management solutions, White Paper. Sep 2007. Available at: http://www-935.ibm.com/services/us/en/businessservices/ibm-asset-management-solutions.html. Accessed on 19th December 2013.

6. Outsourcing. Reference for business. Encyclopedia of business. 2nd ed. Available at: http://www.referenceforbusiness.com/ small/Op-Qu/Outsourcing.html. Accessed on 1st June 2014. 